\title{
Communication
}

\section{A New Flavone $C$-Glycoside from Clematis rehderiana}

\section{Zhi-Zhi Du ${ }^{1}$, Xian-Wen Yang ${ }^{2}$, Hao Han ${ }^{1}$, Xiang-Hai Cai ${ }^{1}$ and Xiao-Dong Luo ${ }^{1, *}$}

1 State Key Laboratory of Phytochemistry and Plant Resources of West China, Kunming Institute of Botany, Chinese Academy of Sciences, Kunming 650204, China;

E-Mail: duzhizhi@mail.kib.ac.cn (Z.-Z.D.)

2 Key Laboratory of Marine Bioresources Sustainable Utilization, South China Sea Institute of Oceanology, Chinese Academy of Sciences, Guangzhou 510301, China;

E-Mail: yangxw76@163.com (X.-W.Y.)

* Author to whom correspondence should be addressed; E-Mail: xdluo@mail.kib.ac.cn.

Received: 24 December 2009; in revised form: 28 January 2010 / Accepted: 29 January 2010 / Published: 29 January 2010

\begin{abstract}
A new flavone $C$-glycoside, isovitexin 6"-O-E-p-coumarate (1) and two known flavonoid glycosides-quercetin 3-O- $\beta$-D-glucuronopyranoside (2) and isoorientin (3) were isolated from an ethanol extract of aerial parts of Clematis rehderiana. Their structures were determined by spectroscopic methods. The antioxidant effects of the two flavone $C$-glycosides were evaluated by both the MTT and DPPH assays. Compound 1 showed potent activities against $\mathrm{H}_{2} \mathrm{O}_{2}$-induced impairment in PC12 cells within the concentration range tested, whereas compound 3 scavenged DPPH radical strongly, with an $\mathrm{IC}_{50}$ value of $13.5 \mu \mathrm{M}$.
\end{abstract}

Keywords: Clematis rehderiana; flavonoide glycosides; antioxidant

\section{Introduction}

The genus Clematis (Ranunculaceae), which comprises about 300 species, is widespread throughout the World. About 147 species (93 endemic ones) are distributed in China, and 56 of these are distributed in Yunnan province [1,2]. It is reported that 77 Clematis species have been used in traditional Chinese medicine, of which 32 are found in Yunnan province [3]. The genus Clematis has many different pharmacological effects such as antibacterial, anti-inflammatory, antitumor, analgesic 
and diuretic functions [4]. Reports on the chemical components of genus Clematis have been scarce up to now and mainly refer to triterpenoid saponins [4-6]. In order to provide some knowledge for better usage of the Clematis resources, we have investigated the chemical constituents and antioxidant activity of Clematis rehderiana from Yunnan.

C. rehderiana (English common name: cowslip scented clematis) is distributed in northwest Yunnan and used by local Tibetan people as a diuretic for eliminating dampness and cure indigestion, lumps in the abdomen and skin ulcers [7]. To the best of our knowledge, there are no reports about the chemical constituents of the species. We report here the isolation and characterization of one new and two known flavonoid glycosides from this plant, as well as antioxidant assay results for two of these compounds.

\section{Results and Discussion}

\section{Structure Elucidation}

The extract of C. rehderiana obtained with $90 \% \mathrm{EtOH}$ was then successively partitioned between $\mathrm{H}_{2} \mathrm{O}$ and EtOAc, followed by $\mathrm{H}_{2} \mathrm{O}$ and $n$-butanol. The $n$-butanol soluble fraction was separated by different chromatographic procedures to afford one new $C$-flavone glycoside $\mathbf{1}$ and two known flavonoid glycosides 2 and 3. Their structures were determined by examination of their spectral data and comparison of the data with reported literature values.

Compound 1 was obtained as a yellow powder. The molecular formula $\mathrm{C}_{30} \mathrm{H}_{26} \mathrm{O}_{12}$ was determined based on the high resolution FABMS data $\left(\mathrm{m} / \mathrm{z} 577.1352[\mathrm{M}-\mathrm{H}]^{-}\right.$, calcd: 577.1346$)$. It gave a positive green coloration with $1 \% \mathrm{FeCl}_{3}$ reagent suggesting it was a flavonoid. The ${ }^{1} \mathrm{H}-\mathrm{NMR}$ spectrum of 1 (Table 1) analyzed with the aid of HSQC and HMBC, showed two hydroxyl proton signals at $\delta_{\mathrm{H}} 13.64$ and $\delta_{\mathrm{H}}$ 9.88; two one-proton singles at $\delta_{\mathrm{H}} 6.54$ and $\delta_{\mathrm{H}} 6.63$, attributed to $\mathrm{H}-8$ and $\mathrm{H}-3$, respectively; and two doublets at $\delta_{\mathrm{H}} 7.91\left(2 \mathrm{H}, \mathrm{d}, J=8.8 \mathrm{~Hz}, \mathrm{H}-2^{\prime}, 6^{\prime}\right)$ and $\delta_{\mathrm{H}} 6.98\left(2 \mathrm{H}, \mathrm{d}, J=8.8 \mathrm{~Hz}, \mathrm{H}-3^{\prime}, 5^{\prime}\right)$, suggesting that 1 was a 5,7,4'-trihydroxyflavone derivative. The ${ }^{1} \mathrm{H}-\mathrm{NMR}$ also showed sugar proton signals at $\delta_{\mathrm{H}} 3.54(2 \mathrm{H}, \mathrm{m}), 3.70(1 \mathrm{H}, \mathrm{m}), 4.12(1 \mathrm{H}, \mathrm{m}), 4.34(1 \mathrm{H}, \mathrm{dd}, J=6.0,12 \mathrm{~Hz}), 4.56(1 \mathrm{H}$, dd, $1.52,12.0 \mathrm{~Hz}), 4.92(1 \mathrm{H}, \mathrm{d}, J=9.8 \mathrm{~Hz})$ attributed to $\mathrm{H}-4 "$ and 5"; 3"; 2"; 6"; 6" and the anomeric proton $\mathrm{H}-1$ ". The position of attachment of the sugar moiety to the flavonol skeleton was determined by HMBC experiments which showed long range coupling between the anomeric $\mathrm{H}-1$ " $(\delta 4.92)$ and the $\mathrm{C}-5$ at $\delta 161.7$ and $\mathrm{C}-7$ at $\delta 164.1$. The ${ }^{1} \mathrm{H}$ - and ${ }^{13} \mathrm{C}$-NMR spectroscopic data of the aglycone and sugar moieties of 1 were similar to those of isovitexin [8], except for the presence of nine additional carbon signals. These nine carbon signals are compatible with an E-p-coumaroyl moiety [9]. Two doublets at $\delta_{\mathrm{H}} 6.85(\mathrm{~J}=8.6 \mathrm{~Hz})$ and $\delta_{\mathrm{H}} 7.53(\mathrm{~J}=8.6 \mathrm{~Hz})$ were attributed to H-3"'/H-5"' and H-2"'/H6 "'of the E-p-coumaroyl moiety, respectively. Two other doublets $(J=15.9 \mathrm{~Hz})$ at $\delta_{\mathrm{H}} 6.37$ and $\delta_{\mathrm{H}} 7.62$ were assigned to H-8"' and H-7"' of the p-coumaroyl moiety with E-configuration, respectively. The acylation of C-6" with a p-coumaroyl unit was deduced from the downfield shift of $\mathrm{CH}_{2}-6^{\prime \prime}$ diastereomeric protons $(\sim+1 \mathrm{ppm})$ and its ${ }^{13} \mathrm{C}$-resonance at $64.7(+4 \mathrm{ppm})$. This evidence was confirmed by the HMBC correlation between $\delta_{\mathrm{H}} 4.34,4.56\left(\mathrm{H}-6^{\prime \prime}\right)$ and $\mathrm{C}-9{ }^{\prime \prime}$ at $\delta 167.5$ Figure 1). Based on the spectral data, the structure of $\mathbf{1}$ was characterized as the new natural product isovitexin $6 "-O-E$-p-coumarate (Figure 2). 
Compound 2 was isolated as a yellow powder and had a molecular formula of $\mathrm{C}_{21} \mathrm{H}_{18} \mathrm{O}_{13}$, as determined by the high resolution FABMS $\left(\mathrm{m} / \mathrm{z} 477.0669[\mathrm{M}-\mathrm{H}]^{-}\right)$. The ${ }^{1} \mathrm{H}-\mathrm{NMR}$ showed two doublets at $\delta_{\mathrm{H}} 6.83\left(1 \mathrm{H}, \mathrm{d}, J=8.3 \mathrm{~Hz}, \mathrm{H}-2^{\prime}\right)$ and $\delta_{\mathrm{H}} 7.42\left(1 \mathrm{H}, \mathrm{br} \mathrm{d}, J=8.2 \mathrm{~Hz}, \mathrm{H}-6^{\prime}\right)$ and one singlet at $\delta_{\mathrm{H}} 8.05\left(\mathrm{H}-5^{\prime}\right)$, suggesting (ortho)-hydroxylation of the B-ring, whereas 5,7-dihydroxylation of A-ring was duduced from two meta-coupled doublets that appeared as br-singlets at $\delta_{\mathrm{H}} 6.39(\mathrm{H}-8)$ and $\delta_{\mathrm{H}}$ $6.19(\mathrm{H}-6)$. The presence of a glucuronide moiety was suggested by the signals at $\delta_{\mathrm{H}} 3.11-3.25(3 \mathrm{H}$, $\left.\mathrm{m}, \mathrm{H}-2^{\prime \prime}, 3^{\prime \prime}, 4^{\prime \prime}\right), \delta_{\mathrm{H}} 5.32\left(\mathrm{H}-1^{\prime \prime}\right)$ and a set of carbon signals at $\delta_{\mathrm{C}} 102.4\left(\mathrm{C}-1^{\prime \prime}\right), 74.1$ (C-2"), $76.4(\mathrm{C}-$ 3"), $71.7\left(\mathrm{C}-4^{\prime \prime}\right), 74.7\left(\mathrm{C}-5^{\prime \prime}\right)$ and 171.7 (C-6"). The assignment of ${ }^{1} \mathrm{H}-$ and ${ }^{13} \mathrm{C}-\mathrm{NMR}$ resonances for the glucuronide moiety were decided by HMBC and H-H COSY correlations, as well as comparison with the reported literature data [10]. The position of attachment of glucuronide moiety to the flavonol skeleton was determined by HMBC experiments which showed long range correlation ( ${ }^{3} \mathrm{~J}$-coupling) between the anomeric proton $\mathrm{H}-1$ " $(\delta 5.32)$ and the $\mathrm{C}-3$ ( $\delta$ 133.8). It was further confirmed by the absence of the characteristic H-3 proton singlet at around $\delta_{\mathrm{H}} 6.7$ associated with the C-3 in the C-ring [10]. Therefore, compound 2 was identified as quercetin 3-O- $\beta$-D-glucuronopyranoside (miquelianin; Figure 2). Finally, compound 3 was identified as isoorientin (Figure 2) by its spectral data (Table 1) and comparison of this data with the reported literature values [8].

Table 1. ${ }^{1} \mathrm{H}$ - and ${ }^{13} \mathrm{C}-\mathrm{NMR}$ data of compounds $\mathbf{1}$ and $\mathbf{3}$ in DMSO ( $\delta$ in ppm, $J$ in $\left.\mathrm{Hz}\right) .{ }^{*}$

\begin{tabular}{cccc}
\hline \multirow{2}{*}{ Position } & \multicolumn{2}{c}{ Compound 1 } & Compound 3 \\
\cline { 2 - 4 } & $\delta_{\mathbf{C}}$ & $\delta_{\mathbf{H}}$ & $\delta_{\mathbf{C}}$ \\
\hline 2 & 164.9 & & 163.7 \\
3 & 103.7 & $6.63(\mathrm{~s})$ & 102.8 \\
4 & 183.1 & & 181.9 \\
5 & 161.7 & & 160.7 \\
6 & 109.0 & & 108.9 \\
7 & 164.1 & & 163.3 \\
8 & 95.0 & $6.54(\mathrm{~s})$ & 93.5 \\
9 & 157.7 & & 156.2 \\
10 & 104.8 & & 103.4 \\
$1^{\prime}$ & 122.5 & & 121.5 \\
$2^{\prime}$ & 129.0 & $7.91(\mathrm{~d}, 8.8)$ & 113.3 \\
$3^{\prime}$ & 116.8 & $6.98(\mathrm{~d}, 8.8)$ & 145.8 \\
$4^{\prime}$ & 162.4 & & 149.8 \\
$5^{\prime}$ & 116.8 & $6.98(\mathrm{~d}, 8.8)$ & 116.1 \\
$6^{\prime}$ & 129.0 & $7.91(\mathrm{~d}, 8.8)$ & 119.0 \\
$1^{\prime \prime}$ & 74.9 & $4.92(\mathrm{~d}, 9.8)$ & 73.1 \\
$2^{\prime \prime}$ & 72.3 & $4.12(\mathrm{~m})$ & 70.2 \\
$3^{\prime \prime}$ & 79.4 & $3.70(\mathrm{~m})$ & 79.0 \\
$4^{\prime \prime}$ & 71.3 & $3.54(\mathrm{~m})$ & 70.7 \\
$5^{\prime \prime}$ & 79.7 & $3.54(\mathrm{~m})$ & 81.7 \\
$6^{\prime \prime}$ & 64.7 & $4.56(\mathrm{dd}, 1.52,12.0)$ & 61.6 \\
& & $4.34(\mathrm{dd}, 6.0,12.0)$ & \\
$1^{\prime \prime \prime}$ & 126.3 & & \\
$2^{\prime \prime \prime}$ & 130.9 & $7.53(\mathrm{~d}, 8.6)$ & \\
\hline
\end{tabular}


Table 1. Cont.

\begin{tabular}{cccc}
\hline \multirow{2}{*}{ Position } & \multicolumn{2}{c}{ Compound 1 } & Compound 3 \\
\cline { 2 - 4 } & $\delta_{\mathrm{C}}$ & $\delta_{\mathbf{H}}$ & $\delta_{\mathrm{C}}$ \\
\hline $3^{\prime \prime}$ & 116.6 & $6.85(\mathrm{~d}, 8.6)$ & \\
$4^{\prime \prime \prime}$ & 161.1 & & \\
$5^{\prime \prime \prime}$ & 116.6 & $6.85(\mathrm{~d}, 8.6)$ & \\
6"' & 130.9 & $7.53(\mathrm{~d}, 8.6)$ & \\
$7 " '$ & 145.7 & $7.62(\mathrm{~d}, 15.9)$ & \\
$8^{\prime \prime \prime}$ & 114.9 & $6.37(\mathrm{~d}, 15.9)$ & \\
$9^{\prime \prime \prime}$ & 167.5 & & \\
\hline
\end{tabular}

${ }^{* 1} \mathrm{H}$ - and ${ }^{13} \mathrm{C}-\mathrm{NMR}$ spectra were obtained at 500 and $125 \mathrm{MHz}$, respectively

Figure 1. Key HMBC interactions of compound 1.

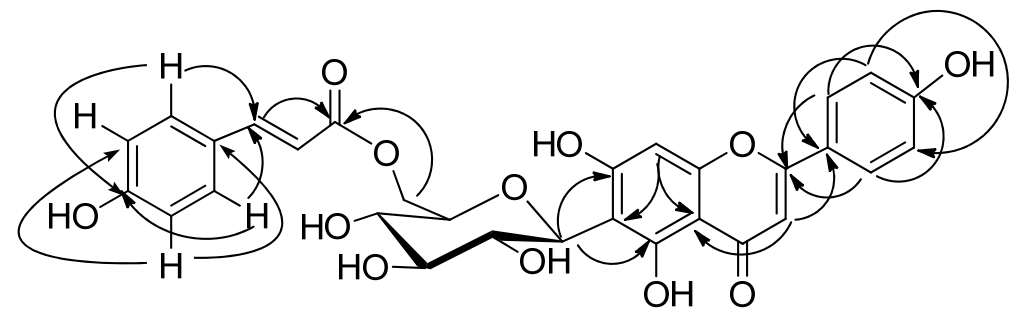

Figure 2. Structures of compounds 1-3.

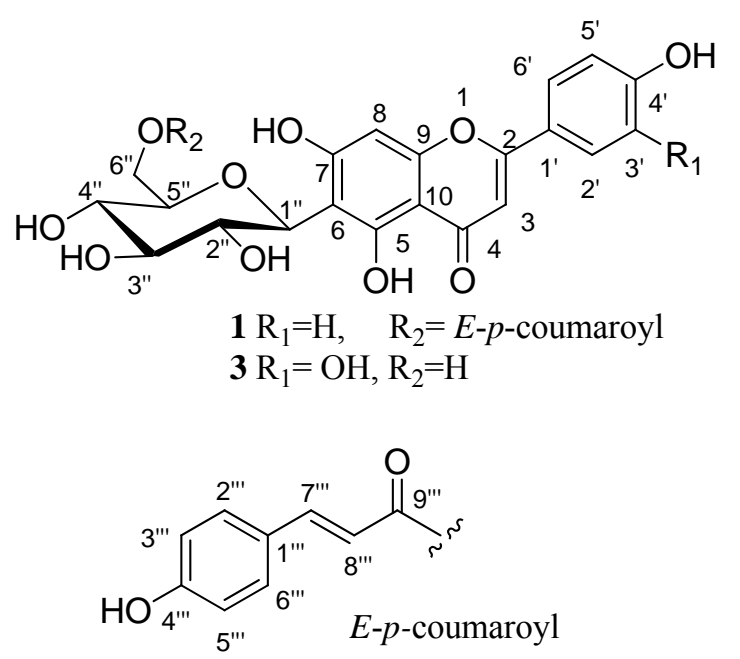

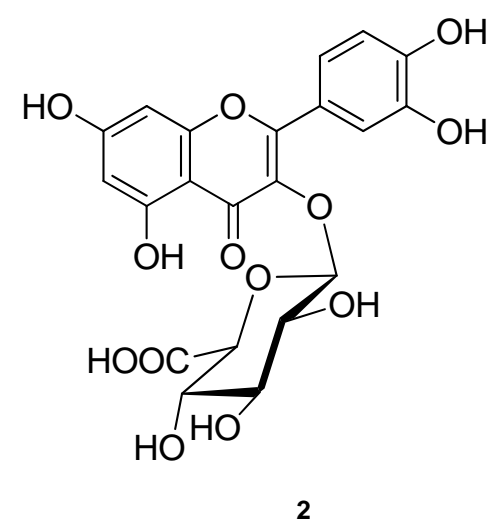

\section{Biological Activity}

Since phenolics are characterized by antioxidant activities [11-14], two isolates were subjected to antioxidant activity experiments using both the MTT and DPPH assays (Tables 2 and 3). Compound 1 showed potent activity against $\mathrm{H}_{2} \mathrm{O}_{2}$-induced impairment in $\mathrm{PC} 12$ cells within the concentration range tested $(0.4$ to $50 \mu \mathrm{M})$, whereas isoorientin (3) scavenged DPPH radical strongly, with an $\mathrm{IC}_{50}$ value of 13.5 $\mu \mathrm{M}$. This indicated that compound $\mathbf{1}$ might be an indirectly acting antioxidant, while $\mathbf{3}$ might be a directly acting antioxidant. 
Table 2. Antioxidant effects of compounds $\mathbf{1}$ and 3 against $\mathrm{H}_{2} \mathrm{O}_{2}$-induced impairment in PC12 cells.

\begin{tabular}{lll}
\hline Groups & Concentration $(\boldsymbol{\mu M})$ & Viability (\%) \\
\hline Control & & 100 \\
Model $^{a}$ & & $40.4 \pm 4.6 * * *$ \\
Edaravone $^{b}$ & 10.0 & $35.3 \pm 3.2$ \\
& 2.0 & $43.2 \pm 4.0$ \\
& 0.4 & $46.1 \pm 2.0 *$ \\
& 0.08 & $44.3 \pm 2.5$ \\
Compound 1 & 50.0 & $64.9 \pm 9.8 * * *$ \\
& 10.0 & $53.7 \pm 7.0 * *$ \\
& 2.0 & $46.1 \pm 6.6$ \\
Compound 3 & 0.4 & $47.6 \pm 10.2$ \\
& 50.0 & $43.7 \pm 4.8$ \\
& 10.0 & $46.7 \pm 5.2$ \\
& 2.0 & $44.9 \pm 6.8$ \\
& 0.4 & $44.5 \pm 6.2$ \\
\hline
\end{tabular}

${ }^{a}$ Negative control; ${ }^{b}$ Positive control; $n=5 ; * p<0.05 ; * * p<0.01 ; * * * p<0.001$ vs. model.

Table 3. Radical scavenging activities of compound $\mathbf{1}$ and $\mathbf{3}$ against DPPH.

\begin{tabular}{cc}
\hline Compounds & IC $_{\mathbf{5 0}}(\boldsymbol{\mu M})$ \\
\hline Edaravone $^{a}$ & 26.0 \\
$\mathbf{1}$ & $>100$ \\
$\mathbf{3}$ & 13.5 \\
\hline
\end{tabular}

${ }^{a}$ Positive control.

\section{Experimental}

\section{General}

Optical rotations were measured with a JASCO DIP-370 digital polarimeter in MeOH solutions. IR spectra were measured on a Bio-Rad FTS-135 infrared spectrometer with KBr pellets. UV spectra were obtained with a Shimadzu UV-2401PC spectrometer. Mass spectra were measured on a VG Auto Spec-3000 spectrometer. NMR spectra were recorded on a DRX-500 NMR spectrometer with TMS as internal standard. Silica gel (200-300 mesh) for column chromatography and precoated TLC plates (Si gel G) were purchased from the Qingdao Marine Chemical Factory (Qingdao, P. R. China). Reversed-phase $\mathrm{C}_{18}$ silica gel for column chromatography were obtained from Merck. Sephadex LH20 for column chromatography was purchased from Amersham Biosciences.

\section{Plant material}

Aerial parts of Clematis rehderiana was collected from Lijian in Yunnan Province, China, in August 2005. A voucher specimen (KUN0816301) is stored at the herbarium of Kunming Institute of Botany, Chinese Academy of Sciences. 


\section{Extraction and isolation}

The air-dried aerial parts of C. rehderiana (3 kg) were ground and extracted four times with $90 \%$ $\mathrm{EtOH}(8 \mathrm{~L}$ each time) at room temperature. After removal of the solvent, the residue was suspended in water $(2 \mathrm{~L})$ and then extracted successively with petroleum ether $(\mathrm{PE})$, EtOAc and $n$-butanol $(4 \times 2 \mathrm{~L}$ each). The $n$-butanol extract was subjected to column chromatography (CC) over macroporous resin D101 eluting with EtOH- $\mathrm{H}_{2} \mathrm{O}(0 \%-95 \%)$ and afforded five fractions Fr. I-V. Fr. III (18.1 g) was subjected to $\mathrm{CC}$ over silica gel $(100 \mathrm{~g})$ and eluted with $\mathrm{CHCl}_{3} / \mathrm{MeOH} 20: 1 \rightarrow 9: 1 \rightarrow 4: 1 \rightarrow 7: 3$ and EtOH to give 10 subfractions (Fr. III1 - Fr. III10). Fr. III5 was further isolated by repeated vacuum liquid chromatography (VLC) over RP-18 and eluted with $\mathrm{MeOH}-\mathrm{H}_{2} \mathrm{O}(0 \%$ to $50 \%)$ to afford compounds 2 (4 mg) and $3(50 \mathrm{mg})$. Fr. IV (3.9 g) was subjected to CC over silica gel $(60 \mathrm{~g})$ and eluted with $\mathrm{CHCl}_{3} / \mathrm{MeOH}$ 20:1 $\rightarrow$ 9:1 $\rightarrow$ 7:3 to give 14 subfractions (Fr. IV1 - Fr. III14). Fr. IV8 was further fractionated by repeated $\mathrm{CC}$ over SephadexLH-20 and eluted with $\mathrm{MeOH}-\mathrm{CHCl}_{3}$ and $\mathrm{MeOH}$ to afford compound $\mathbf{1}(12 \mathrm{mg})$.

Compound 1: $[\alpha]_{\mathrm{D}}^{25}=+32.9$ (c 0.76, MeOH); IR (KBr): 3,420, 2,920, 1,720 $\mathrm{cm}^{-1} ;{ }^{1} \mathrm{H}-$ and ${ }^{13} \mathrm{C}-\mathrm{NMR}$ see Table 1. HRFABMS (neg): m/z 577.1352 [M-H] $]^{-}$, calcd: 577.1346.

Compound 2: $[\alpha]_{\mathrm{D}}^{25}=-8.6\left(\right.$ c 0.58, MeOH); UV (MeOH) $\lambda_{\max }(\log \varepsilon) 404,270,210 \mathrm{~nm}$; IR (KBr): 3,408, 2,922, 1,653, 1,604; HRFABMS (neg): m/z 477.0669 [M-H] ${ }^{-}$, calcd: 477.0669; ${ }^{1} \mathrm{H}-\mathrm{NMR}$ $\left(\mathrm{DMSO}_{6}\right) \delta: 12.35\left(1 \mathrm{H}\right.$, br s 5-OH), $8.05\left(1 \mathrm{H}, \mathrm{s}, \mathrm{H}-5^{\prime}\right), 7.42\left(1 \mathrm{H}, \mathrm{br} \mathrm{d}, J=8.2 \mathrm{~Hz}, \mathrm{H}-6^{\prime}\right), 6.83(1 \mathrm{H}, \mathrm{d}$, $\left.J=8.3 \mathrm{~Hz}, \mathrm{H}-2^{\prime}\right), 6.39$ (1H, br s, H-8), $6.19\left(1 \mathrm{H}\right.$, br s, H-6), $5.32\left(1 \mathrm{H}, \mathrm{d}, J=7.0 \mathrm{~Hz}, \mathrm{H}-1^{\prime \prime}\right), 3.391 \mathrm{H}$, m, H-5"), 3.11-3.25 (3H, m, H-2", 3", 4"); ${ }^{13} \mathrm{C}-\mathrm{NMR}$ (DMSO-d $)$ ): 157.2 (C-2), 133.8 (C-3), 177.4 (C-4), 161.0 (C-5), 98.9 (C-6), 164.5 (C-7), 93.7 (C-8), 156.4 (C-9), 103.7 (C-10), 120.6 (C-1'), 115.3 (C-2'), 144.8 (C-3'), 148.5 (C-4'), 117.5 (C-5'), 120.9 (C-6'), 102.4 (C-1"), 74.1 (C-2"), 76.4 (C-3"), $71.7\left(\mathrm{C}-4^{\prime \prime}\right), 74.7$ (C-5"), $171.7\left(\mathrm{C}-6^{\prime \prime}\right)$.

\section{Antioxidant assays}

The antioxidant assay against $\mathrm{H}_{2} \mathrm{O}_{2}$-induced impairment in $\mathrm{PC} 12$ cells was conducted according to the reported protocol [14]. Briefly, PC12 cells were seeded into 96-well plates in RPMI 1640 medium with 10\% characterized Newborn Bovine Serum. Twenty-four hours later, different concentrations of compounds 1 and 3 together with freshly prepared $\mathrm{H}_{2} \mathrm{O}_{2}$ were added and incubation continued for 1 hour. Then MTT (3-(4,5-dimethylthiazol-2-yl)-2,5-diphenyltetrazolium bromide) solution was added and the incubation continued for 4 hours. Finally, solution $(100 \mu \mathrm{L})$ containing $5 \%$ iso-butanol, 10\% SDS (Sigma) and $0.004 \% \mathrm{HCl}$ was added. The mixtures were kept overnight and the index of cell viability ( $\%$ of control) was calculated by measuring the optical density of the color produced by MTT dye reduction with a microplate reader at $570 \mathrm{~nm}$.

DPPH radical-scavenging activity assays were performed according to our previously reported procedures [11]. Each compound $(100 \mu \mathrm{L})$ at five different concentrations was added to DPPH solution $(100 \mu \mathrm{L})$. The absorbance was measured with a microplate reader at $517 \mathrm{~nm}$ after $30 \mathrm{~min}$ of reaction at $37^{\circ} \mathrm{C}$. $\mathrm{IC}_{50}$ values denote the concentration of sample required to scavenge $50 \% \mathrm{DPPH}$ free radicals. 


\section{Conclusions}

A new flavone $C$-glycoside, isovitexin 6"-O-E-p-coumarate (1) and two known flavonoid glycosides - quercetin 3-O- $\beta$-D-glucuronopyranoside (2) and isoorientin (3)-were isolated from an ethanol extract of aerial parts of $C$. rehderiana. The antioxidant effects experiments of these compounds by both the MTT and DPPH assays suggested that flavone glycosides were major constituents with antioxidant activities in this plant.

\section{Acknowledgements}

This work was partially supported by the "Xi-Bu-Zhi-Guang" Project funded by the Chinese Academy of Sciences; the Natural Science Foundation of Yunnan Province (2009CD111) and MarieCurie Incoming International Fellowship (MC-IFF-039253) under the EU's Sixth Framework Programme. We thank the analytical group of the State Key Laboratory of Phytochemistry and Plant Resources in West China, Kunming Institute of Botany, for spectral measurements.

\section{References}

1. Wang, W.C.; Bartholomew, B. Ranunculaceae. In Flora of China, 1st ed.; Wu, Z.Y., Peter, H.R., Eds.; Science Press: Beijing, China, 2001; Volume 6, pp. 333-386.

2. Wang, W.C.; Li, L.Q. Ranunculaceae. In Flora Yunnanica, $1^{\text {st }}$ Edition; Kunming Institute of Botany; Science Press: Beijing, China, 2000; Volume 11, pp. 208-253.

3. Chen, W.Y.; Pu, C.X. Resource Investigation of Medicinal Species of Clematis in Yunnan Province. J. Yunnan College Trad. Chin. Med. 2006, 29, 31-33.

4. Song, Z.H.; Zhao, Y.Y.; Duan, J.L.; Wang, X. Review of chemical constituents and pharmacological actions of Clematis species. Nat. Prod. Res. Dev. 1996, 7, 67-72.

5. Liu, L.F.; Ma, X.L.; Wang, Y.X., Li, F.W., Li, Y.M., Wan, Z.Q., Tang, Q.L. Triterpenoid saponins from the roots of Clematis chinensis Osbeck, J. Asian Nat. Prod. Res. 2009, 11, 389-396.

6. Huang, W.W. Advances in studies on chemical constituents and pharmacological effect of Clematis L. Chin. Tradition. Herbal Drugs 2002, 33, 285-290.

7. Yang J.S.; Chuchen J.C. Diqing Tibet Herb, 1st ed.; Yunnan Ethnic Publishing House: Kunming, China, 1987; pp. 192-194.

8. Peng, J.Y.; Fan, G.R.; Hong, Z.Y.; Chai Y.F.; Wu Y.T. Preparative separation of isovitexin and isoorientin from Patrinia villosa Juss by high-speed counter-current chromatography. J. Chromatogr. A 2005, 1074, 111-115.

9. Andrade, F.D.P.; Santos L.C.; Dokkedal A.L.; Vilegas W. Acyl glucosylated flavonols from Paepalanthus species. Phytochemistry 1999, 51, 411-415.

10. Lu, Y.R.; Foo, L.P. Flavonoid and phenolic glycosides from Salvia officinalis. Phytochemistry 2000, 55, 263-267.

11. Yang, X.W.; Zhao, P.J.; Ma, Y.L.; Xiao, H.T.; Zuo, Y.Q.; He, H.P.; Li, L.; Hao, X.J. Mixed lignan-neolignans from Tarenna attenuata. J. Nat. Prod. 2007, 70, 521-525. 
12. Yang, X.W.; Wang, J.S.; Ma, Y.L.; Xiao, H.T.; Zuo, Y.Q.; Lin, H.; He, H.P.; Li, L.; Hao, X.J. Bioactive phenols from the leaves of Baccaurea ramiflora. Planta Med. 2007, 73, 1415-1417.

13. Yang, X.W.; He, H.P.; Du, Z.Z.; Liu, H.Y.; Di, Y.T.; Ma, Y.L.; Wang, F.; Lin, H.; Zuo, Y.Q.; Li, L.; Hao, X.J. Tarennanosides A-H, eight new lignan glucosides from Tarenna attenuata and their protective effect on $\mathrm{H}_{2} \mathrm{O}_{2}$-induced impairment in PC12 cells. Chem. Biodivers. 2009, 6, 540-550.

14. Yang, X.W.; Wang, J.S.; Wang, Y.H.; Xiao, H.T.; Hu, X.J.; Mu, S.Z.; Ma, Y.L.; Lin, H.; He, H.P.; Li, L.; Hao, X.J. Tarennane and tarennone, two novel chalcone constituents from Tarenna attenuata. Planta Med. 2007, 73, 496-498.

Sample Availability: Samples of the compounds are available from the authors.

(C) 2010 by the authors; licensee Molecular Diversity Preservation International, Basel, Switzerland. This article is an open-access article distributed under the terms and conditions of the Creative Commons Attribution license (http://creativecommons.org/licenses/by/3.0/). 